\title{
Efficacy of radiotherapy in normalizing serum IGF-I, acid-labile subunit (ALS) and IGFBP-3 levels in acromegaly
}

Paolo Epaminonda, Silvia Porretti, Vincenzo Cappiello, Paolo Beck-Peccoz, Giovanni Faglia and Maura Arosio Institute of Endocrine Sciences, University of Milano, Ospedale Maggiore IRCCS, Milano, Italy

(Received 17 November 2000; returned for revision 10 December 2000; finally revised 16 October 2000; accepted 23 February 2001)

\section{Summary}

OBJECTIVE Radiotherapy (RT) has been used for many years in order to complete the cure of unsuccessfully operated acromegalic patients. Several studies have shown its efficacy in normalizing GH levels, while reports about IGF-I normalization are conflicting. Moreover, data regarding other markers of disease activity, such as IGFBP-3 and acid-labile subunit (ALS), i.e. the other two components of the circulating $150 \mathrm{kDa}$ complex, are lacking.

DESIGN Retrospective study.

PATIENTS AND MEASUREMENTS Sixty-seven acromegalic patients (20 males and 47 females, aged $40 \pm 6$ years) who underwent postoperative RT (in fractionated doses for a total of 40-75 Gy) were followed-up for $11 \pm 6$ years (range: 1-26 years, median: 10 years). Serum GH and IGF-I levels off medical therapy were measured in all patients; ALS and IGFBP-3 were measured in 11 patients with normalization of IGF-I concentrations. Computed tomography or nuclear magnetic resonance imaging periodically assessed possible development of pituitary deficiency along with imaging of the hypothalamic-pituitary region.

RESULTS Forty-one out of 67 patients (58\%) achieved GH levels $<2.5 \mu \mathrm{g} / \mathrm{l}$ by $1-15$ years after RT (mean $8 \pm 6$ ) and $37 / 67$ patients (55\%) had normal or low IGF-I levels 1-26 years after RT (mean: $12 \pm 6$ ), a normalization of both parameters being

Correspondence: Maura Arosio, Institute of Endocrine Sciences, Ospedale Maggiore, Pad. Granelli, Via F. Sforza, 35, 20122 Milano, Italy. Fax: +39 025519 5438; E-mail: maura.arosio@unimi.it seen in 37 patients. GH $<2.5 \mu \mathrm{g} / \mathrm{l}$ and normal IGF-I levels were achieved in 17/26 (65\%) patients followedup for at least 15 years. ALS and IGFBP-3 concentrations paralleled IGF-I levels in all patients studied. With respect to secondary pituitary insufficiency, acquired ACTH deficiency was found in 25 patients, TSH deficiency in 20, gonadotropin deficiency in 23 and GH deficiency in seven. In total, two cases of meningioma and one pineal tumour, possibly related to RT, were seen 9-22 years after RT.

CONCLUSIONS RT is an effective, although slowacting, therapeutic tool for acromegaly, with 'safe' GH levels and normal IGF-I concentrations being achieved in $65 \%$ of patients after 15 years. IGF-I levels normalize more slowly than GH levels. Radiotherapy is able to normalize the concentration of all three components of the circulating $150 \mathrm{kDa}$ complex. Checks for loss of pituitary function and appearance of second brain tumours must be carried out life-long.

Conventional external radiotherapy has been used for many years in the treatment of acromegaly. In fact, most reports show that, after 2 years, GH concentrations decrease by approximately $50 \%$ from baseline and, after 5 years, by approximately $75 \%$, with an overall rate of success of $50-90 \%$ at $10-15$ years (Eastman et al., 1992; Goffman et al., 1992; Jaffe, 1999). If the actual more restrictive criteria to define the control of acromegalic disease are taken into account, i.e. GH serum levels $<1 \mu \mathrm{g} / \mathrm{l}$ after oral glucose load, and mean baseline $\mathrm{GH}<2.5 \mu \mathrm{g} / \mathrm{l}$ ('safe GH levels') (Bates et al., 1993; Giustina et al. 2000), the success rate in controlling GH hypersecretion is probably lower, accounting for 20-30\% (Gorden et al., 1987; Thalassinos et al., 1998). Moreover, serum IGF-I levels are considered an important marker of disease activity in acromegaly, with their normalization being an inalienable part of the concept of cure of acromegaly (Frohman, 1996). Surprisingly, it was recently claimed that, at variance with GH, IGF-I serum levels do not normalize in acromegalic patients treated with radiotherapy, thus suggesting a dissociated effect on GH and IGF-I levels (Barkan et al., 1997). Nothing is known about radiotherapy effects on the other components of ternary complex, i.e. acid-labile subunit (ALS) and IGFBP-3, the levels 
of which are good additive parameters of active acromegaly (Grinspoon et al., 1995; Baxter, 1997). To further study this issue, we have retrospectively re-evaluated the effects of conventional radiotherapy on GH and IGF-I levels in all irradiated acromegalic patients seen at our Institute who were followed-up for a minimum of 1 year. ALS and IGFBP-3 levels were also measured in a small subgroup of patients who normalized IGF-I concentrations. Finally, because RT frequently induces hypopituitarism and, more rarely, second brain tumours, side-effects were evaluated.

\section{Patients and methods}

\section{Patients}

We included in the present study 67 patients ( 47 females and 20 males, mean age at the time of radiotherapy: $40 \cdot 5 \pm 6$ years) out of 80 who were diagnosed and/or treated in our Institute and irradiated from 1969 to 1996. Ten patients were excluded because they were followed for a period of time shorter than 1 year, and three because they lacked IGF-I measurements. Sixty-two patients underwent previous unsuccessful pituitary surgery ( 61 by a transnasosphenoidal and one by a transfrontal approach), while five patients had radiotherapy as the primary treatment. Seventy percent of patients were irradiated at our Hospital with a three-field technique, using a ${ }^{60} \mathrm{Co}$ source, while no information could be obtained on the technique used for the remaining patients who were treated elsewhere. The mean dose delivered was 53.6 Gy (range: 40-75), fractionated in 30-35 sessions (1.5-1.8 Gy for each application). Three patients received two cycles of radiotherapy 4-8 years apart. After radiotherapy, 11 patients were treated with somatostatin analogues alone, 24 patients with dopaminergic drugs and six with both. However, all the data reported in the present paper were obtained during adequate withdrawal of medical therapy ( 1 month for the 12 patients treated with octreotide s.c. and three months for the five patients treated with lanreotide $30 \mathrm{mg}$ i.m.).

\section{Protocol}

Before radiotherapy, each patient was evaluated for serum GH levels (mean of at least three serial serum samples) and anteropituitary function (basal PRL, TSH, LH, FSH, cortisol, thyroid hormones, testosterone in males and 17-beta oestradiol in females, TSH response to TRH, gonadotropin response to $\mathrm{GnRH}$ and cortisol response to insulin hypoglycemia or low dose, $1 \mu \mathrm{g}$ ACTH test). Posterior pituitary function was evaluated on clinical grounds. IGF-I levels were available before therapy in 28 patients. The follow-up after radiotherapy ranged from 1 to 26 years (12 \pm 6 years, median: 10 years). Serum GH was measured at each visit, with IGF-I starting from
1986. Only hormonal assessment carried out off medical therapy were considered. Data were analysed at 1, 2, 3, 4, 5, 10 (taking into account the nearest data obtained at \pm 6 months for the first 5 years and between 8 and 12 years for 10 years), 13-15 and more than 15 years after the execution of radiotherapy cycles. Complete pituitary function studies were performed approximately every 3 years. ALS and IGFBP-3 were measured in 11 patients with apparent normalization of IGF-I concentrations. The samples were all taken in the fasting state.

\section{Hormone assays}

Serum GH values were measured over the years by different assays: a double antibody radioimmunoassay (RIA), using anti-hGH supplied by NIH and ${ }^{125}$ I hGH supplied by CEACEN-Sorin (Saluggia, Italy) until 1975; HGH RIA Kit, Dow Lepetit (Milano, Italy) until 1982; HGH RIA LISOPHASE, Sclavo (Milano, Italy) until 1992 and a fluoroimmunoassay (AutoDELFIA $^{\mathrm{TM}} \mathrm{hGH}$, Wallac Oy, Turku, Finland) in the most recent years. This latter assay has a detectability level of $0.01 \mu \mathrm{g} / \mathrm{l}$, and intra- and interassay coefficients of variation of $4.1 \%$ and $9 \%$, respectively. The three oldest kits utilized standards calibrated against the WHO first IRP HGH-MRC 66/ $217(1 \mu \mathrm{g} / \mathrm{l}=2 \mathrm{mIU} / \mathrm{l})$, while AutoDELFIA uses standards calibrated against NIH 1RP 80/505 $(1 \mu \mathrm{g} / \mathrm{l}=2.6 \mathrm{mIU} / \mathrm{l})$. The last GH determination for each patient was performed by AutoDELFIA. For the purposes of this study, all GH data were treated similarly. Data are expressed in $\mu \mathrm{g} / \mathrm{l}$.

Serum IGF-I concentrations were measured by commercial RIA kits: from 1986 to 1996, by Incstar (Stillwater, MN, USA) after removal of binding proteins by acidification and filtration on ODS C18 cartridges, with intra- and interassays coefficients of variation of 15 and $16 \%$, respectively; afterwards by Mediagnost (Tübingen, Germany) which succeeds in obtaining separation between IGF-BP and IGF-I by acidification in IGFII excess. The last assay has a detectability level of $0.02 \mathrm{ng} / \mathrm{ml}$, and intra- and interassay coefficients of variation of 3.2 and $8.9 \%$, respectively. In our hands, the results obtained with the two methods have a coefficient of correlation of 0.97 . For both assays, data were compared with an appropriate age-adjusted range obtained in 100 healthy adult controls, ranging from 20 to $61 \mathrm{nmol} / \mathrm{l}$ at 18 years to $6-26 \mathrm{nmol} / \mathrm{l}$ at 70 years. For each patient, the last IGF-I measurement was performed by Mediagnost.

Total ALS was measured by means of specific two-site sandwich enzyme-linked immunosorbent assay, using anti ALS antibodies raised against synthetic amino-terminal and carboxyterminal ALS peptides, reagents and tracer provided by Diagnostic System Laboratories (Webster, TX, USA). All samples were pretreated in order to dissociate the complexed ALS and enhance ALS immunoreactivity. The sensitivity of the 


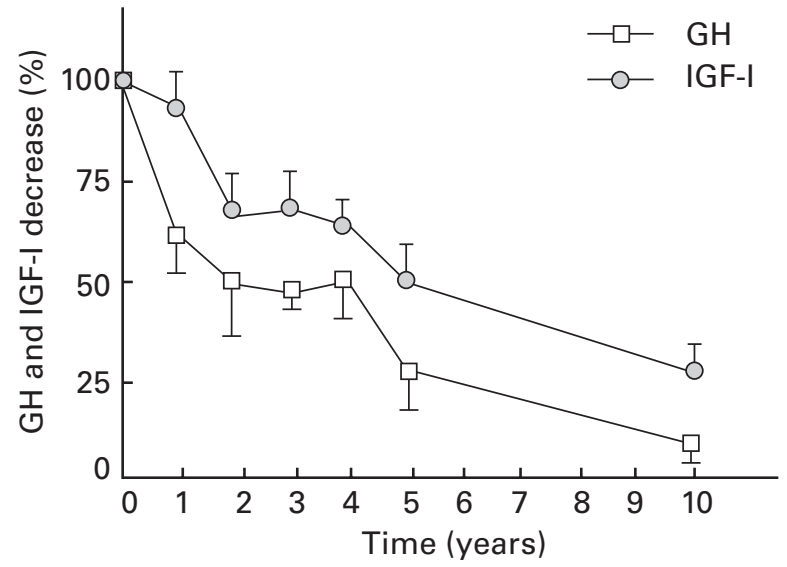

Fig. 1 Percentage decrease of GH and IGF-I levels (mean \pm SE) in 26 acromegalic patients.

assay was $400 \mathrm{ng} / \mathrm{ml}$; the intra-assay and interassay coefficients of variation were 5.5 and $7.2 \%$, respectively. Recovery of the human serum-derived glycosylated ALS was $75 \%$ for the lowest concentration added $(1 \mu \mathrm{g})$ and $95 \%$ for the highest concentration added $(60 \mu \mathrm{g})$. The normal range, determined in 100 healthy adult subjects, is $216-350 \mathrm{nmol} / \mathrm{l}$, without any significant agerelated modifications in adult life (Barreca et al., 1999).

IGFBP-3 was measured by immunometric assay, using reagents and tracer provided by Diagnostic System Laboratories (Webster, TX, USA) as previously described (Barreca $e t$ al., 1995). The sensitivity of the assay is $1.5 \mathrm{ng} / \mathrm{ml}$; the intraand interassay coefficients of variation are 3.25 and $5.6 \%$, respectively.

Normal levels, determined in 100 healthy adult subjects, range from 71 to $140 \mathrm{nmol} / \mathrm{l}$ at 18 years to $42-126 \mathrm{nmol} / \mathrm{l}$ at 70 years.

\section{Statistical analysis}

All data were expressed as the mean \pm SD unless otherwise stated. Relationship between parameters was determined by Pearson's correlation. $P<0.05$ was considered statistically significant.

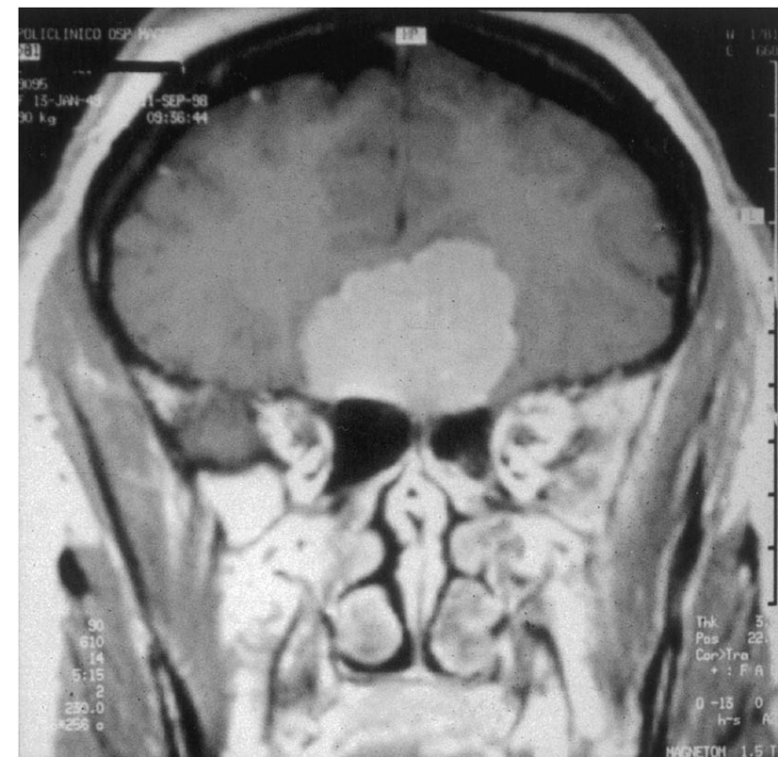

Fig. 2 Coronal magnetic resonance imaging view of a possibly radiotherapy-induced voluminous meningioma in an acromegalic patient (histology: meningotheliomatous meningioma).

\section{Results}

\section{Pre-radiotherapy assessment}

Before radiotherapy, basal mean serum GH levels were $20 \cdot 2 \pm 27 \mu \mathrm{g} / \mathrm{l}$, ranging from $3 \cdot 2$ to $190 \mu \mathrm{g} / \mathrm{l}$. Eight patients were hyperprolactinaemic (mean: $37.6 \mu \mathrm{g} / \mathrm{l}$; range: $24-64$ ), six patients were hypothyroid, four hypoadrenal and one hypogonadal. Mean IGF-I levels, measured in 28 patients, were $110 \cdot 8 \pm 48 \mathrm{nmol} / \mathrm{l}$, ranging from 47 to $243 \mathrm{nmol} / \mathrm{l}$ (all IGF-I levels were high if compared with age-matched controls).

\section{Overall effects of radiotherapy on $\mathrm{GH}$ levels}

GH concentrations decreased to below $2.5 \mu \mathrm{g} / \mathrm{l}$ in 41 out of 67 patients $(61 \%)$ after a mean of $8 \pm 6$ years. Radiotherapy preceded the achievement of low GH levels of a period ranging

Table 1 Percentage of patients who normalized GH and IGF-I levels in relationship with pretreatment values and time elapsed from radiotherapy

\begin{tabular}{lcccc} 
Time & Percentage of patients & Baseline GH levels $(\mu \mathrm{g} / \mathrm{l})$ & Percentage of patients & Baseline IGF-I levels (nmol/l) \\
\hline 0-3 years & 22 & $5 \cdot 9 \pm 2$ & 12 & $51 \pm 21$ \\
$3-4$ years & 9 & $7 \cdot 7 \pm 4$ & 0 & - \\
$4-5$ years & 6 & $9 \cdot 1 \pm 5$ & 12 & $93 \pm 25$ \\
$5-10$ years & 12 & $24 \cdot 6 \pm 25$ & 31 & $92 \cdot 4 \pm 39$ \\
$>10$ years & 12 & $19 \cdot 3 \pm 11$ & 0 & - \\
Never & 39 & $43 \cdot 0 \pm 49$ & 45 & $132 \pm 50$ \\
\end{tabular}


Table 2 Pituitary deficiency in irradiated patients

\begin{tabular}{lcr}
\hline $\begin{array}{l}\text { Pituitary } \\
\text { deficiency }\end{array}$ & $\begin{array}{c}\text { No. of } \\
\text { patients }(\%)\end{array}$ & $\begin{array}{c}\text { Mean time } \\
\text { at diagnosis (years) }\end{array}$ \\
\hline ACTH & $25(37 \%)$ & $6 \pm 6$ \\
TSH & $20(30 \%)$ & $4 \pm 5$ \\
LH/FSH & $23(34 \%)$ & $7 \pm 5$ \\
GH & $7(10 \%)$ & $15 \pm 6$ \\
\hline
\end{tabular}

from 1 to 20 years, being longer than 5 years in $40 \%$ of patients. The delay in the achievement of these GH levels was largely dependent on GH concentration at baseline (Table 1).

\section{Overall effects of radiotherapy on IGF-I, ALS and IGFBP-3 levels}

Serum IGF-I normalized in 37/67 patients after $12 \pm 6$ years (range: 1-26 years). Among these patients, 55\% normalized IGF-I concentrations after more than 5 years and one-third after more than 10 years.

We did not observe any patient with normal IGF-I values and GH levels $>2.5 \mu \mathrm{g} / \mathrm{l}$, while four patients who achieved 'safe' serum GH levels did not normalize IGF-I levels. Ten patients showed IGF-I levels below the third percentile for age (mean time at diagnosis: $15 \pm 6$ years post RT). In seven of these patients, a deficiency of GH secretion was confirmed by an absent GH increase after an insulin tolerance test (ITT) or combined GHRH-arginine administration. Serum ALS and IGFBP-3 measured in 11 acromegalics who achieved normal IGF-I concentrations and GH levels below $2.5 \mu \mathrm{g} / \mathrm{l}$ were also normalized. In these patients, ALS levels ranged from 160 to $341 \mathrm{nmol} / 1$ (mean: $240 \pm 10$ ), and IGFBP-3 from 48 to $127 \mathrm{nmol} / \mathrm{l}$ (mean: $85 \pm 1 \cdot 7$ ). In the three patients with low IGF-I levels, ALS concentrations were low, while IGFBP-3 concentrations were normal in one patient and in the lownormal range in two.

\section{Long-term efficacy of radiotherapy}

Among the 26 patients followed for 15 or more years, 17 (65\%) achieved safe GH and normal IGF-I levels. Nine patients who did not normalize hormonal parameters, even after 15 or more years, showed quite stable GH and IGF-I levels in the last years.

\section{Comparison between effects on $\mathrm{GH}$ and IGF-I levels}

Twenty-six patients had IGF-I measured before radiotherapy. The decrease of GH and IGF-I levels showed a significant correlation $(r=0.951, P<0.001)$. However, while mean GH serum levels showed a $39 \%$ decrease in the first year after radiotherapy (from $14.7 \mu \mathrm{g} / \mathrm{l}$ to $9.1 \mu \mathrm{g} / \mathrm{l}$ ), halved at 2 years and were diminished by $95 \%$ at 10 years, IGF-I levels showed a slower decrease over the years. In fact, only a 5\% reduction was seen in the first year, a 35\% reduction during the second year, halved at fifth year; and were reduced by $75 \% 10$ years after radiotherapy (Fig. 1).

Both serum GH and IGF-I levels before therapy appear to be good predictors of efficacy of radiotherapy: in fact, basal GH and IGF-I levels of patients who achieved 'safe' GH levels were significantly lower than the basal levels of the patients who did not $(12$ vs. $42 \mu \mathrm{g} / \mathrm{l}$ and $86.5 \pm 37$ vs. $143 \cdot 1 \pm 42 \mathrm{nmol} / \mathrm{l}$, for GH and IGF-I, respectively).

\section{Other pituitary function}

Before RT, eight patients were hyperprolactinaemic and 59 normoprolactinaemic. Half of the hyperprolactinaemic patients normalized PRL concentrations 2-5 years after RT, but only in one case was this finding associated with the achievement of safe GH and IGF-I levels. Before radiotherapy, six patients were hypothyroid, four hypoadrenal and one hypogonadal. After radiotherapy, one or more anterior pituitary deficiencies occurred in $60 \%$ of patients. Radiotherapy-induced ACTH deficiency occurred in 25 patients $(36 \%$ ) (mean time at diagnosis: $6 \pm 6$ years post RT, range: 1-20 years), TSH deficiency in $20(30 \%)$ (mean time at diagnosis: $4 \pm 5$ years post RT, range: 1-18 years), gonadotropin deficiency in 23 (34\%) (mean time at diagnosis: $7 \pm 5$ years following radiotherapy; range: 1-18 years). (Table 2). It is of note that all six patients who received doses higher than 55 Gy developed panhypopituitarism.

\section{Radiotherapy-induced tumours}

Three tumours involving brain-areas near to the field of irradiation were observed 9-22 years after radiotherapy: two meningiomas and one neoplasm of unknown histology. The two meningiomas were 1 and $4 \mathrm{~cm}$, respectively (Fig. 2), were completely asymptomatic and were diagnosed only by a NMR imaging routine follow-up. At the time of diagnosis, patients showed normal IGF-I and very low GH levels. Both patients had received one cycle of radiotherapy at the dose of 54 Gy. They underwent successful surgery, and histology confirmed that the masses were meningiomas. The third patient showed neurological symptoms and signs in 1983, 13 years after the first and 9 years after a second cycle of radiotherapy (total dose approximately 72 Gy). A computed tomography scan showed a pineal mass that caused hydrocephalus. Treated by radiotherapy the patient was then lost at follow-up and died 
3 years later. When he died, normalization of GH and IGF-I levels had not occurred. No cases of optic nerve damage or cranial nerve palsies were observed.

\section{Discussion}

The present data show that radiotherapy is able to normalize IGF-I levels and the other two components of the circulating ternary complex, IGFBP-3 and ALS, besides GH. Our rate of GH percent fall is superimposable to that reported previously (Gorden et al., 1987; Jaffe, 1999). We observed IGF-I normalization in $55 \%$ of the patients. This finding is lower than that described by Ciccarelli et al. (1993) with a normalization of IGF-I levels in 68\% (follow-up: 2-4 years) and by Biermasz et al. (2000) who observed $84 \%$ of patients with normal IGF-I 15 years after RT. Our data are indeed more similar to those of Af Trampe et al. (1991) who report normalization of IGF-I levels in 57\% out of 40 patients 312 years postirradiation, and to those of Powell et al. (2000) who observed normal IGF-I levels in approximately $40 \%$ of patients after a mean of 5.2 years. These studies report a slower decrease in IGF-I levels in respect to GH, with the earliest significant decrease of IGF-I mean levels being observed after 2 years, a year later than that observed for GH (Ciccarelli et al., 1993). In contrast, an almost complete ineffectiveness of pituitary irradiation to normalize serum IGFI was claimed by Barkan et al. (1997) and Thalassinos et al. (1998), with normalization of IGF-I in 5\% after a mean of 7 years and $28 \%$ after 10 years, respectively. Although it is difficult to find a fully satisfactory explanation for these discrepant data, it should be stressed that both length of followup and basal GH levels are of paramount importance in evaluating the results of radiotherapy. In both of these studies, the average duration of follow-up was 3-4 years shorter than ours. In addition, most of the patients studied by Thalassinos et al. received radiotherapy without previous surgery and had pretreatment GH levels higher than the patients of the present study. Four patients from the present series presented elevated IGF-I levels with low mean fasting GH levels (below 2 and even $1 \mu \mathrm{g} / \mathrm{l})$. Similar observations have been reported by others (Powell et al. 2000), suggesting that radiotherapy may induce an abnormal pattern of GH release and pulsatility, with a greater 'nonpulsatile' release of GH in irradiated patients with respect to normal controls (Jaffe, 1999; Peacey \& Shalet, 1999). This abnormal release of GH would induce a continued stimulation of IGF-I.

IGF-I is for the most part bound to a circulating complex of $150 \mathrm{kDa}$ constituted by a specific IGF-binding protein (IGFBP-3), and by an ALS besides IGF-peptide. These two proteins are GH-dependent, and their use as markers of integrated GH secretion is well established. They offer the advantage over IGF-I of a simpler measurement, being unaffected by IGFBPs which interfere in IGF-I assays and, as far as ALS is concerned, of a minor age-dependency. Approximately $90 \%$ of untreated patients show high ALS concentrations (Hoffman et al., 1997; Arosio et al., 2001) and elevated IGFBP-3 concentrations of approximately 75\% (Arosio et al., 2001; Thissen et al., 1996).

Successful surgery has been shown to normalize ALS and IGFBP-3 levels. The absence of elevated levels of ALS or IGFBP-3 in the subgroup of patients with normal IGF-I is a further demonstration that radiotherapy is indeed able to cure acromegaly. Further studies will be necessary to understand whether the decreases in the levels of ALS/BP3 more closely mirrors decreases in GH or IGF-I. In addition ALS, but not IGFBP-3, was shown to be an index as sensitive as IGF-I in detecting a growth hormone deficiency. In our study, a highly positive correlation between basal and final $\mathrm{GH}$ values was found. This is concordant with previous findings of a higher frequency and earlier appearance of 'normal' GH levels after RT in patients with lower pretreatment GH levels (Littley et al., 1990; Ciccarelli et al., 1993; Jaffe, 1999). This observation may be extended to basal IGF-I levels, which can be considered, together with $\mathrm{GH}$ levels, as an important predictive factor of RT efficacy. This stresses the importance of therapeutical tools, such as surgery, which should be performed before radiotherapeutical applications to improve its efficacy, and definitively rejects RT as a primary therapeutic choice. Progressive hypopituitarism is a wellknown sequela of radiotherapy. In this regard, our data are fully concordant with those reported in the literature (Af Trampe et al., 1991; Ciccarelli et al., 1993; Eastman et al., 1992; Thalassinos et al., 1998). An important aspect is that $10 \%$ of patients who showed GH hypersecretion became $\mathrm{GH}$ deficient after radiotherapy. Because GH deficiency is characterized by an increase in morbidity and mortality that is not less than acromegaly, a definitive diagnosis (by means of IGF-I evaluation and, if necessary, stimulation testing) must be performed. If $\mathrm{GH}$ deficiency is confirmed, an adequate treatment with rhGH has to be started. Biermasz et al. (2000) reported a higher percentage of GH deficiency $(36 \%)$ using ITT. This testing may overestimate the real prevalence of GH deficiency because abnormal GH responses to ITT are described in active acromegaly.

In addition, the possibility of radiotherapy-induced neoplasia is well known. We reported three cases of encephalic tumours located near the irradiated hypothalamic-pituitary region found after $10-20$ years. These are likely due to radiotherapy. This fact indicates that the risk of radiotherapyinduced neoplasia is extremely low but still present, even in the modern mega-voltage era (Parker, 1990; Ahmed et al., 1997). The percentage of radiotherapy-induced malignancies in our 
study is high when compared with the results reported by Brada et al. (1992) (1.9\% at 20 years) and by other studies (Tsang et al., 1993; Barcelò et al., 1998) regarding the effects of radiotherapy in secreting and non-secreting pituitary adenomas. It is tempting to speculate that increased IGF-I levels may act as a possible carcinogenic factor (Khandwala et al. 2000), and may increase the risk of a second tumour in irradiated acromegalic patients in contrast to patients harbouring different kinds of pituitary tumours. It is important to note that two out of the three cases of secondary brain tumours were clinically silent, and have been detected after a close surveillance by nuclear magnetic resonance imaging and a long follow-up. This fact stresses once again the importance of careful life-long follow-up in irradiated patients even if they are asymptomatic and cured.

In conclusion, radiotherapy still remains an effective tool to treat acromegaly. However, using modern, more stringent criteria, its efficacy does not appear to be as high as previously reported. It may cause serious side-effects and requires lifelong follow-up of patients.

\section{Acknowledgements}

The authors wish to thank Professor A. Barreca, DISEM, University of Genova, for kind determination of ALS and IGFBP-3 concentrations. The present study was partially supported by research grants 9906153187-00 from Ministero dell'Università e della Ricerca Scientifica (MURST, Rome) and from Ospedale Maggiore IRCCS (Milano).

\section{References}

Af Trampe, E., Lundell, G., Lax, I. \& Werner, S. (1991) External irradiation of growth hormone producing pituitary adenomas: prolactin as a marker of hypothalamic and pituitary effects. International Journal of Radiation Oncology, Biology and Physics, 20, 655-660.

Ahmed, M., Kanaan, I., Rifdai, A., Tulbah, A. \& Ghannam, N. (1997) An unusual treatment-related complications in a patient with growth hormone-secreting pituitary tumor. Journal of Clinical Endocrinology and Metabolism, 82, 2816-2820.

Arosio, M., Ciarrone, S., Bruzzi, P., Faglia, G., Minuto, F. \& Barreca, A. (2001) Diagnostic value of the acid-labile subunit in acromegaly evaluation in comparison with insulin-like growth factor (IGF) I and IGF-binding protein-1, -2 and -3. Jounal of Clinical Endocrinology and Metabolism, 86, 1096-1098.

Barcelò, B., Vàzquez, G. \& Magallòn, R. (1998) Long-term adverse effects of radiotherapy. In Pituitary Tumors: Epidemiology, Pathogenesis and Management (ed. S.M. Webb), pp. 127-145. BioScientifica Ltd., Bristol.

Barkan, A.L., Halasz, I., Dornfeld, K.J., Jaffe, C.A., DeMott Friberg, R., Chandler, W.F. \& Sandler, H.M. (1997) Pituitary irradiation is ineffective in normalising plasma insulin-like growth factor I in patients with acromegaly. Journal of Clinical Endocrinology and Metabolism, 82, 3187-3191.

Barreca, A.M., Cariola, G., Ponzani, P., Arvigo, M., Foppiani, L., Giordano, G. \& Minuto, F. (1995) Effect of octreotide on circulating IGF-I chromatographic profile: evidence for an inhibitory action on the formation of the 150-kDa ternary complex. Clinical Endocrinology, 42, 161-167.

Barreca, A.M., Garrone, S., Cesarone, A., Arosio, M., Ghizzoni, L., Giordano, G. \& Minuto, F.M. (1999) Reliability of the acid-labile subunit (ALS) of the $150 \mathrm{kDa}$ IGF complex in GH hyper and hyposecretory states. Proceedings of the 81st Meeting of the Endocrine Society, p. 400 (abstract).

Bates, A.S., Van't Hoff, W., Jones, J.M. \& Clayton, R.N. (1993) An audit of outcome of treatment in acromegaly. Quarterly Journal of Medicine, 86, 293-299.

Baxter, R.C. (1997) Editorial: the binding protein's binding proteinclinical applications of acid-labile subunit (ALS) measurement. Journal of Clinical Endocrinology and Metabolism, 82, 3941-3943.

Biermasz, N.R., Van Dulken, H. \& Roelfsema, F. (2000) Long-term follow up results of postoperative radiotherapy in 36 patients with acromegaly. Journal of Clinical Endocrinology and Metabolism, 85, 2476-2482.

Brada, M., Ford, D., Ashley, S., Bliss, J.M., Crowley, S., Mason, M., Rajan, B. \& Traish, D. (1992) Risk of second brain tumor after conservative surgery and radiotherapy for pituitary adenoma. British Medical Journal, 304, 1343-1346.

Ciccarelli, E., Valetto, M.R., Vasario, E., Avataneo, T., Grottoli, S. \& Camanni, F. (1993) Hormonal and radiological effects of megavoltage radiotherapy in patients with growth hormone-secreting pituitary adenoma. Journal of Endocrinological Investigation, 16, $565-572$.

Eastman, R.C., Gorden, P., Glatstein, E. \& Roth, J. (1992) Radiation therapy of acromegaly. Endocrinology and Metabolism Clinics of North America, 21, 693-712.

Frohman, L.A. (1996) Editorial: acromegaly: what constitutes optimal therapy?. Journal of Clinical Endocrinology and Metabolism, 81, 443-445.

Giustina, A., Barkan, A., Casanueva, F.F., Cavagnini, F., Frohman, L., Ho, K., Veldhuis, J.D., Wass, J., von Werder, K. \& Melmed, S. (2000) Criteria for cure of acromegaly: a consensus statement. Journal of Clinical Endocrinology and Metabolism, 85, 526-529.

Goffman, T.E., Dewan, R., Arakaki, R., Gorden, P., Oldfield, E.H. \& Glatstein, E. (1992) Persistent or recurrent acromegaly. Cancer, 69, 271-275.

Gorden, P., Glatstein, E., Oldfield, E. \& Roth, J. (1987) Conventional supervoltage radiation in the treatment of acromegaly. In Acromegaly (ed. R.J Robbins), pp. 211-220. Plenum, New York.

Grinspoon, S., Clemmons, D., Swearingen, B. \& Klibanski, A. (1995) Serum insulin-like growth factor-binding protein 3 levels in the diagnosis of acromegaly. Journal of Clinical Endocrinology and Metabolism, 80, 927-932.

Hoffman, D.M., Baxter, R.C., O'Sullivan, A.J., Crampton, L. \& Ho, K. (1997) Serum acid-labile subunit in adult growth hormone deficiency and acromegaly (abstract). Endocrinology and Metabolism, 4, (Suppl. A), 23.

Khandwala, H.M., McCutcheon, I.E., Flyvbjerg, A. \& Friend, K.E. (2000) The effects of insulin-like growth factors on tumorigenesis and neoplastic growth. Endocrine Reviews, 21, 215-244.

Jaffe, C.A. (1999) Revaluation of conventional pituitary irradiation in the therapy of acromegaly. Pituitary, 2, 55-62.

Littley, M.D., Shalet, S.M., Swindell, R., Beardwell, C.G. \& Sutton, 
M. (1990) Low-dose pituitary irradiation for acromegaly. Clinical Endocrinology, 32, 261-270.

Parker, R.G. (1990) Radiation-induced cancer as a factor in clinical decision making (the 1989 astro gold medal address). International Journal of Radiation Oncology, Biology and Physics, 18, 993-1000.

Peacey, S.R. \& Shalet, S.M. (1999) Growth hormone pulsatility in acromegalic following radiotherapy. Pituitary, 2, 63-69.

Powell, J.S., Wardlaw, S.L., Post, K.D. \& Freda, P.U. (2000) Outcome of radiotherapy for acromegaly using normalisation of insulin-like growth factor I to define cure. Journal of Clinical Endocrinology and Metabolism, 85, 2068-2071.

Thalassinos, N.C., Tsagarakis, S., Ioannides, G., Tzavara, I. \&
Papavasiliou, C. (1998) Megavoltage pituitary irradiation lowers but seldom leads to safe GH levels in acromegaly: a long-term follow-up study. European Journal of Endocrinology, 138, 160163.

Thissen, J.P., Ketelslegers, J.M. \& Maiter, D. (1996) Use of insulinlike growth factor-I (IGF-I) and IGF-binding protein-3 in the diagnosis of acromegaly and GH deficiency in adults. Growth Regulation, 6, 222-229.

Tsang, R.W., Laperriere, L.J., Simpson, W.J., Brierly, J., Panzarella, T. \& Smith, M.A. (1993) Glioma arising after radiation therapy for pituitary adenoma. A report of four patients and estimation on risk. Cancer, 72, 2227-2233. 